\title{
The study of the anti-inflammatory activity of a stomatological gel based on an extract of Artemisia scoparia Waldst. et Kit.
}

\author{
Dmitry POZDNYAKOV 1 (D), Emma AYRAPETYAN 2 * D, Dmitry KONOVALOV 2 iD
}

1 Department of Pharmacology with a course of clinical pharmacology, Faculty of Pharmacy, Pyatigorsk Medical and Pharmaceutical Institute, branch of the Volgograd State Medical University, Pyatigorsk, Russia.

2 Department of Pharmacognosy, Botany and Technology phytopreparations, Faculty of Fharmacy, Pyatigorsk Medical and Pharmaceutical Institute, branch of the Volgograd State Medical University, Pyatigorsk, Russia.

* Corresponding Author. E-mail: airapetyan0505@mail.ru (E.A); Tel. +7-928-220 2333.

Received: 15 February 2021 / Revised: 07 September 2021/ Accepted: 07 September 2021

ABSTRACT: The objectives of present investigation is to study of the pharmacology activity of a stomatological gel based on an extract of Artemisia scoparia. Ethanol extract of Artemisia scoparia contains chlorogenic acid, scopoletin, umbelliferone and scoparone which have anti-inflammatory activity. Kamistad gel was used as a comparison. Researches show wormwood-based gel has a local anti-inflammatory effect, comparable to that of the reference drug Kamistad.

KEYWORDS: Artemisia scoparia; anti-inflammatory activity; stomatological gel; animals; wormwood.

\section{INTRODUCTION}

Artemisia scoparia Waldst. et Kit. (Asteraceae) is known as Wormwood - an annual, rarely two-year-old aromatic plant, up to $150-180 \mathrm{~cm}$ high. It is widespread throughout the world. In traditional medicine, some countries are used for pain caused by inflammation and fever [1].The chemical composition of the aerial part of Artemisia scoparia is characterized mainly by terpene, phenolic and polyacetylene compounds [2-4].

Research groups from different countries studied some types of pharmacological activity of alcoholwater extracts from the aerial part of Artemisia scoparia $[1,5,6]$. Hydromethanol extract of Artemisia scoparia showed significant anti-nociceptive, anti-inflammatory and antipyretic activity in a model of inflammation in mice. Habib \& Waheed, 2003 assumed that the antinociceptive effect extract of Artemisia scoparia is mediated by the participation of opioid and adenosine receptors. The activity of the extract is due to the action of several active components that differ in the mechanisms of anti-inflammatory action. It is also possible the directly inhibit the general path of pain sensation through the transport of sodium/potassium into the cell [1].

It has recently been reported that an ethanol extract from wormwood has an anti-inflammatory effect on human mast cells, reducing levels of pro-inflammatory cytokines (TNFa, etc) [7].

Among the components of the ethanol extract of Artemisia scoparia as chlorogenic acid, scopoletin, umbelliferone and scoparon have anti-inflammatory activity [8-11].

The anti-inflammatory activity of scoparone is also associated with its ability to inhibit the expression of tissue factor in lipopolysaccharides, which is associated with its antioxidant properties. This prevents the formation of superoxide anion and transcription of tissue factor, which are directly related to the development of various inflammation reactions [4].

\section{RESULTS AND DISCUSSION}

In the test-extract, the following active compounds were identified: scopoletin, umbelliferone, scoparon, chlorogenic acid. It is worth noting that in the analyzed extract, chlorogenic acid was the major component, and scopoletin, umbelliferone and scoparon was found in a smaller amount (Table 1).

How to cite this article: Pozdnyakov D, Ayrapetyan E, Konovalov D. The study of the anti-inflammatory activity of a stomatological gel based on an extract of Artemisia scoparia Waldst. et Kit. J Res Pharm. 2022; 26(1): 189-197. 
Table 1. The results of the quantitative determination of chlorogenic acid, scopoletin, umbelliferone and scoparone in the extract of Artemisia scoparia.

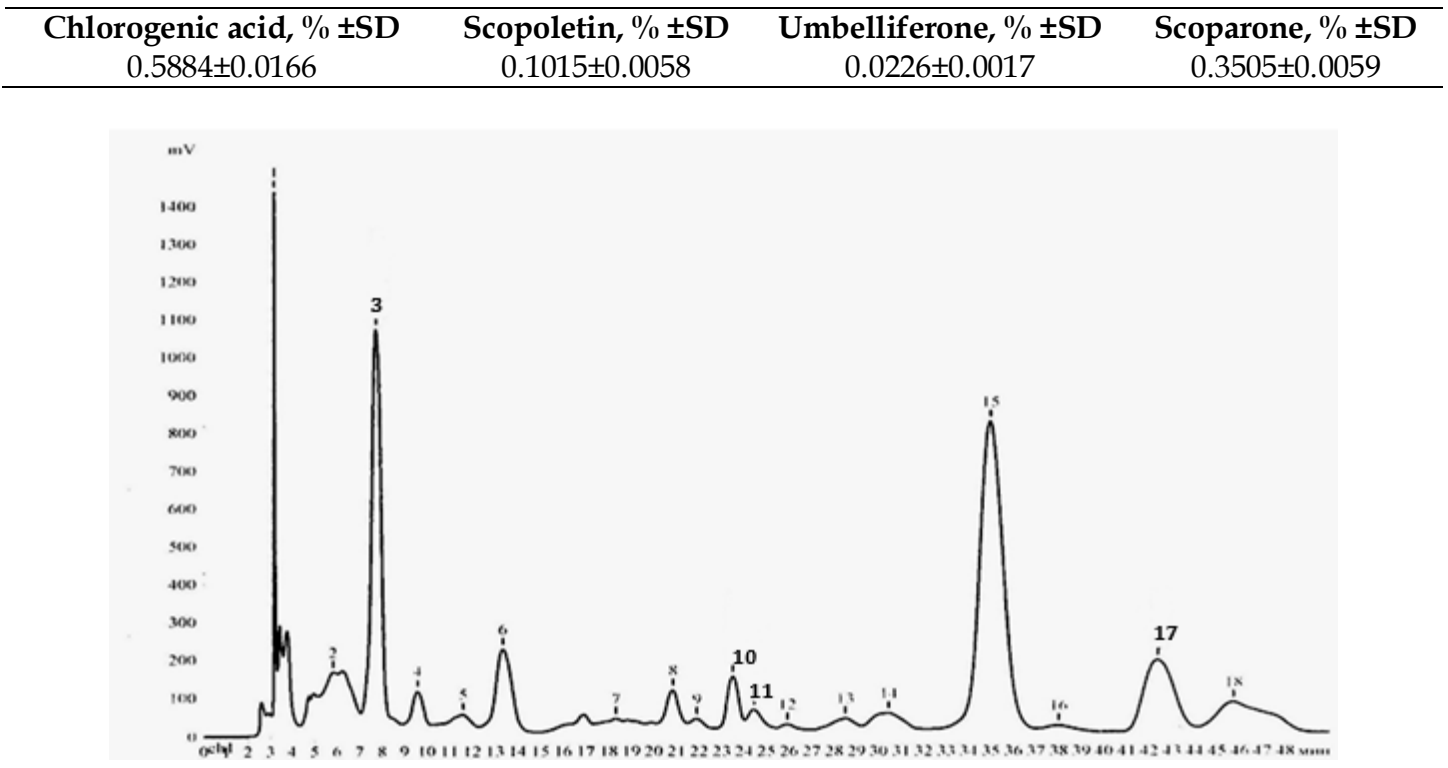

Figure 1. Chromatogram of Artemisia scoparia extract: 3- chlorogenic acid, 10 - scopoletin, 11 umbelliferone, 17 - scoparon.

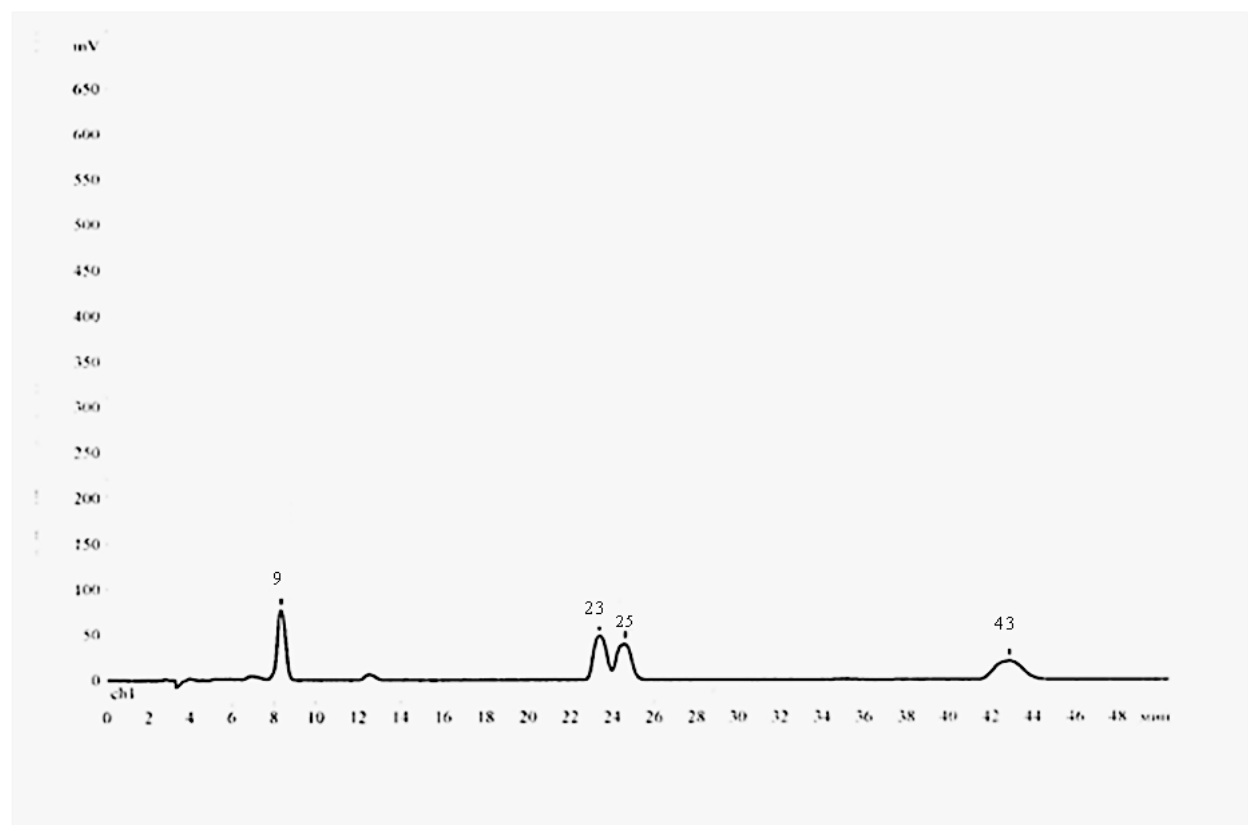

Figure 2. Chromatogram of a model mixture of standard samples: 9- chlorogenic acid, 23 - scopoletin, 25 umbelliferone, 43 - scoparon.

The analytical method was validated according to the following characteristics: specificity, linearity, precision and correctness. The specificity of the method for determining these compounds was confirmed by the correspondence of the retention times of the peaks of the analyzed compounds on the extraction chromatogram and the chromatogram of the solution of the standard samples mixture. Also, the addition of a standard samples mixture was used to determine the specificity, while the asymmetry, efficiency, and peak profile did not change, which indicates the specificity of the method.

The linearity of the method was confirmed by analyzing solutions of chlorogenic acid at 5 different concentration levels. A comparison of the relationship between the content of chlorogenic acid in the obtained solutions and the values of the areas of chromatographic peaks showed that the method has a linear character. The expressions of this dependence are shown in figure 3. 


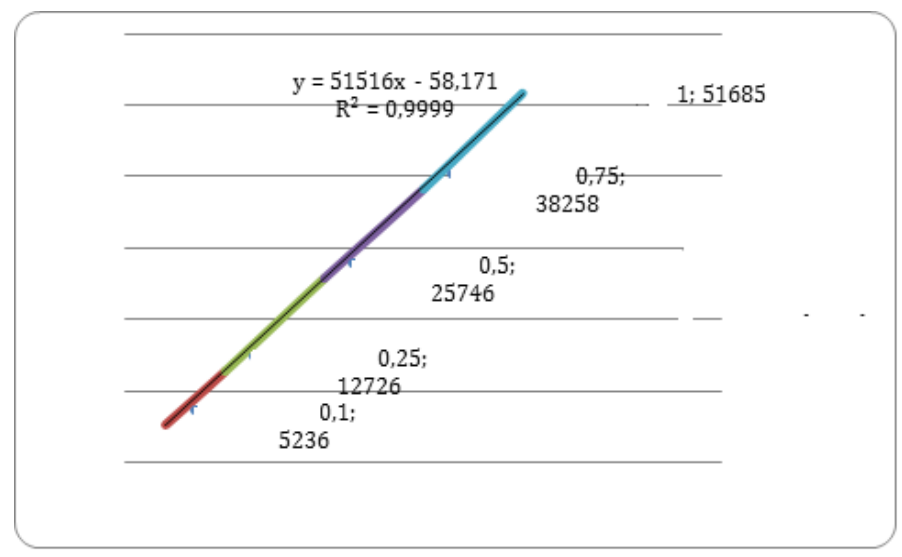

Figure 3. Calibration graph of the dependence of the chromatographic peak areas on the concentration of chlorogenic acid in the standard sample.

The precision was determined at the convergence level. For this purpose, 6 parallel determinations were performed according to the developed methodology. The standard deviation (SD) and the relative standard deviation (RSD) were then calculated.

\subsection{Confirmation of the precision of the method for chlorogenic acid}

The correctness of the method was determined by the additive method, performing 9 tests at 3 concentration levels. The assessment of the correctness of the method was carried out by the openability.

Table 2. Results of determining the precision of the method for the quantitative determination of chlorogenic acid in the extract of wormwood.

\begin{tabular}{cccccc}
\hline No & Raw material, $\mathbf{g}$ & Peak area & $\mathbf{X}, \mathbf{\%}$. & SD & RSD, \% \\
\hline $\mathbf{1}$ & 6.2501 & 4868.25 & 0.1003 & & \\
$\mathbf{2}$ & 6.2504 & 4739.24 & 0.0977 & & \\
$\mathbf{3}$ & 6.2500 & 4916.78 & 0.1013 & & \\
$\mathbf{4}$ & 6.2504 & 4776.54 & 0.0984 & 0.0034 & 3.4 \\
$\mathbf{5}$ & 6.2498 & 4934.65 & 0.1017 & & \\
$\mathbf{6}$ & 6.2497 & 4839.12 & 0.0997 & & \\
& & & Xcp 0.0999 & & \\
\hline
\end{tabular}

In the course of the pharmacological study, it was found that in animals of the NC group, a progressive teeth deterioration and damage of the interdental space was observed, which arose as a result of mechanical trauma. In this group of rats, by the 14th day of the study, the formation of a connective tissue in the area of the wound defect was detected, which subsequently underwent lysis with the formation of purulent exudate. Also, in animals of the NC group, on the 14th day of the study, macroscopically intensification of necrotic processes in the basal space was observed. Visual representation of changes in teeth and interdental space in NC group rats is presented on Figure 4.

When observing changes in the concentration of leukocytes in the blood in animals of the negative control group, an increase in the total number of white blood cells in this group of rats in comparison with the group of intact animals by the 3rd day of the study by 6.8 times $(p<0.05)$ was established. Further, the concentration of leukocytes in the blood of the NC group of rats remained at a fairly high level and at the 7th; 10th and 14th day of the study was higher than the similar parameter of the IA group of animals by 6.9 times $(\mathrm{p}<0.05) ; 8.6$ times $(\mathrm{p}<0.05)$ and 8.5 times $(\mathrm{p}<0.05)$, respectively (Table 3$)$. The change in leukoformula in rats of the NC group occurred due to an increase in the content of monocytes and granulocytes in peripheral blood. Monocyte concentration in blood on the 7th, 10th and 14th day of the study in animals of the NC group exceeded those in intact rats by 2.1 times $(p<0.05) ; 2.2$ times $(p<0.05)$ and 2.1 times $(p<0.05)$, respectively, with an increase in granulocyte content by 1.7 times $(p<0.05) ; 1.8$ times $(p<0.05)$ and 1.8 times ( $\mathrm{p}<0.05$ ), respectively (Table 3 ). The NC group of animals (on the 3rd; 7th; 10 th and 14th day of the experiment) showed an increase in serum CRP concentration relative to the rats of the intact group by 6.7 times $(\mathrm{p}<0.05) ; 6.3$ times $(\mathrm{p}<0.05) ; 5.7$ times $(\mathrm{p}<0.05)$ and 5.2 times $(\mathrm{p}<0.05)$, respectively. This data indicate the development of a systemic inflammatory reaction in the NC group of animals [15]. 
Table 3. Results of determining the correctness of the method of quantitative determination of chlorogenic acid in wormwood extract.

\begin{tabular}{|c|c|c|c|c|c|c|c|}
\hline $\begin{array}{l}\text { № } \\
\text { п }\end{array}$ & Level & $\begin{array}{c}\text { Chlorogenic } \\
\text { acid amount, } \%\end{array}$ & $\begin{array}{c}\text { The amount of } \\
\text { chlorogenic acid } \\
\text { added to the bulk } \\
\text { of the raw } \\
\text { material, } \%\end{array}$ & $\begin{array}{l}\text { Theoretical } \\
\text { amount of } \\
\text { chlorogenic } \\
\text { acid in the } \\
\text { sample, } \%\end{array}$ & $\begin{array}{l}\text { The amount of } \\
\text { chlorogenic } \\
\text { acid found in } \\
\text { the sample, } \%\end{array}$ & $\begin{array}{l}\text { Openability } \\
\text { (R), } \%\end{array}$ & \\
\hline 1 & 1 & 0.588 & 0.472 & 1.060 & 1.024 & 96.6 & \multirow{9}{*}{$\begin{array}{c}\text { Rcp }= \\
100.00 \% \\
\text { RSD }=5.7 \%\end{array}$} \\
\hline 2 & 1 & 0.588 & 0.472 & 1.060 & 1.074 & 101.3 & \\
\hline 3 & 1 & 0.588 & 0.472 & 1.060 & 1.026 & 96.8 & \\
\hline 4 & 2 & 0.588 & 0.590 & 1.178 & 1.204 & 102.2 & \\
\hline 5 & 2 & 0.588 & 0.590 & 1.178 & 1.194 & 101.4 & \\
\hline 6 & 2 & 0.588 & 0.590 & 1.178 & 1.174 & 99.7 & \\
\hline 7 & 3 & 0.588 & 0.708 & 1.296 & 1.315 & 101.5 & \\
\hline 8 & 3 & 0.588 & 0.708 & 1.296 & 1.318 & 101.7 & \\
\hline 9 & 3 & 0.588 & 0.708 & 1.296 & 1.280 & 98.8 & \\
\hline
\end{tabular}

The application of a gel base on a wound defect did not significantly affect the state of the interdental space in animals. In the group of rats that received the gel base as pharmacological support, significant macroscopic differences in the root region of tooth in comparison with the NC group were not detected (Figure 5). In addition, the concentrations of leukocytes (Table 5), CRP (Table 6) and leukoformula changes of rats, which were applied a gel basis, did not statistically significantly different from the similar values of the animal NC group.

In the group of animals treated by Kamistad (in comparison with the NC group of rats), a decrease in the concentration of leukocytes (Table 1) in the blood on the 3rd day of the study by 1.7 times $(p<0.05)$, on the 7th day -2.3 times $(\mathrm{p}<0.05)$, the 10th day -4.8 times $(\mathrm{p}<0.05)$ and the 14th day of the experiment -7.8 times $(\mathrm{p}<0.05)$ was noted. In animals that applicated Kamistad on a wound defect, the monocyte content on the 7th, 10th and 14th day of the study was lower than the analogues indicator of the rat group NC by1.3 times ( $p<0.05), 1.9$ times $(p<0.05)$ and 1.9 times $(p<0.05)$, respectively (Table 5). The concentration of granulocytes in the blood of animals treated by Kamistad decreased throughout the experiment. On the 7th, 10th and 14th day, the content of granulocytes in peripheral blood decreased by 1.3 times $(p<0.05) ; 1.6$ times $(p<0.05)$ and 1.8 times $(p<0.05)$ relative to the NC group of rats. Moreover, the serum CRP concentration in animals treated by Kamistad was lower in comparison with rats of the NC group by 1.5 times $(\mathrm{p}<0.05) ; 2.3$ times ( $p<0.05)$; 3.1 times $(\mathrm{p}<0.05)$ and 3.5 times $(\mathrm{p}<0.05)$ on the $3 \mathrm{rd}, 7 \mathrm{th}, 10$ th and 14 th day of the study, respectively. Macroscopic analysis of the root region of tooth in a group of rats treated by Kamistad revealed the presence of a small connective tissue site, which tended to decrease by the 14th day of the study (Figure $6)$.

The use of Artemisia scoparia gel caused a decrease of the leukocytes concentration in the blood of rats on the 3rd, 7th, 10th and 14th day of the experiment by 1.6 times ( $p<0.05) ; 1.9$ times ( $<<0.05) ; 6.2$ times ( $p$ $<0.05)$ and 6.5 times $(\mathrm{p}<0.05)$, respectively, relative to the group of NC animals. In addition, in rats treated by wormwood gel, the content of monocytes in peripheral blood was lower on the 7th day of the study - by 1.5 times $(\mathrm{p}<0.05)$; on the 10th day -1.9 times $(\mathrm{p}<0.05)$ and the 14 th day -1.8 times $(\mathrm{p}<0.05)$ in comparison with a group of animals, without pharmacological support. Also, the use of the studied wormwood gel reduced the concentration of granulocytes in the blood on the 7th, 10th and 14th day of the experiment by 1.2 times ( $p<0.05) ; 1.5$ times $(\mathrm{p}<0.05)$ and 1.7 times $(\mathrm{p}<0.05)$, respectively, relative to the NC group of rats (Table 5). 


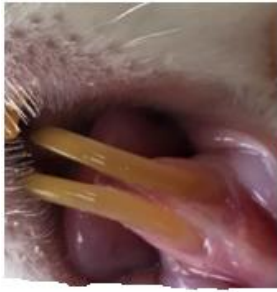

Day 3

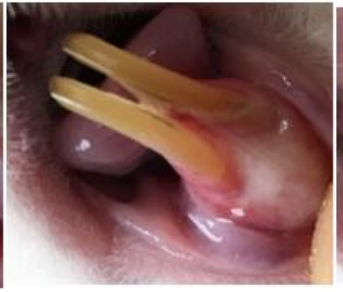

Day 7

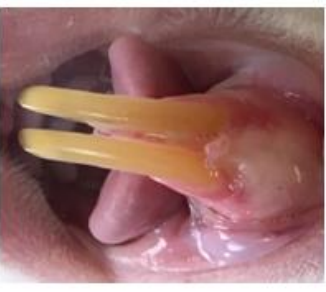

Day 10

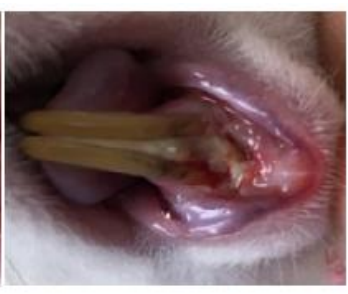

Day 14

Figure 4. Macroscopic assessment of changes in the state of the interdental space in animals of the NC group after traumatic injury.

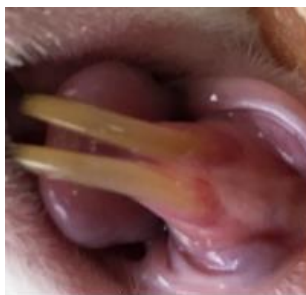

Day 3

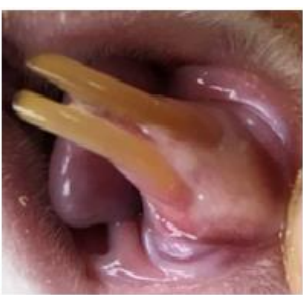

Day 7

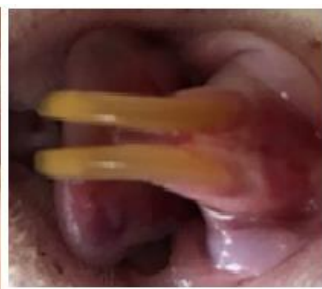

Day 10

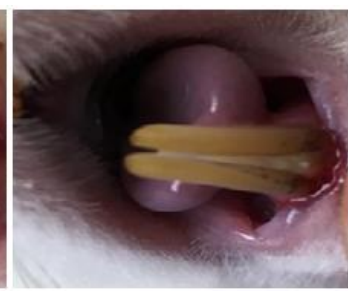

Day 14

Figure 5. Macroscopic assessment of changes in the state of the interdental space in a group of animals that received a gel base after traumatic tooth injury.

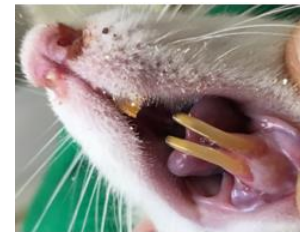

Day 3

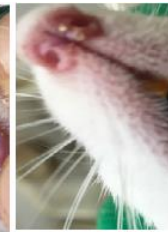

Day 7

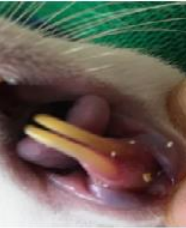

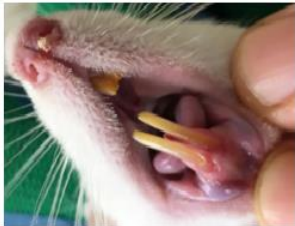

Day 10

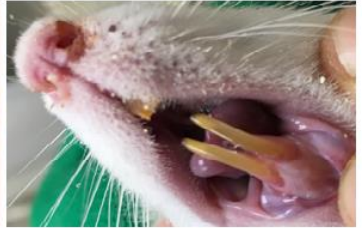

Day 14

Figure 6. Macroscopic assessment of changes in the state of the interdental space in a group of animals treated with Kamistad after traumatic injury.

In the group of animals treated by wormwood gel, the content of CRP in rat serum on the 3rd, 7th, 10th and 14th day of the study, was lower by 1.6 times $(\mathrm{p}<0.05) ; 2.0$ times $(\mathrm{p}<0.05) ; 3.9$ times $(\mathrm{p}<0.05)$ and 4.0 times $(p<0.05)$ respectively than in the NC group of animals (Table 6 ).

No statistically significant differences between groups of rats treated by wormwood gel and Kamistad were found. Moreover, the macroscopic picture of the change in the interdental space in rats treated by wormwood gel corresponded to that in the group of animals treated by Kamistad (Figure 7).

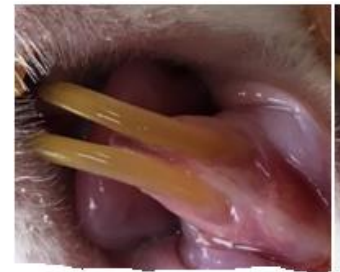

Day 3

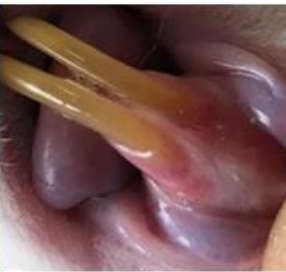

Day 7

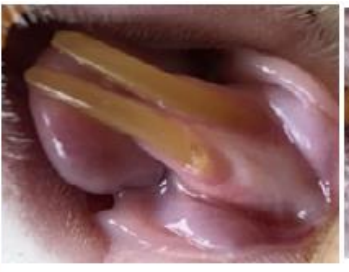

Day 10

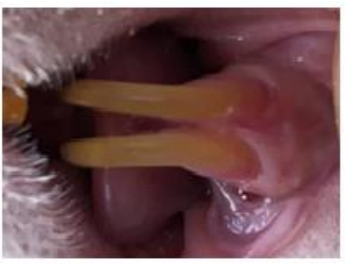

Day 14

Figure 7. Macroscopic assessment of changes in the state of the interdental space in a group of animals treated with wormwood gel after traumatic tooth injury.

\section{CONCLUSION}

Thus, based on the change in the macroscopic picture of the wound defect, the concentration of leukocytes in the blood, and the content of C-reactive protein in the blood serum, it can be assumed that the studied object - wormwood-based gel has a local anti-inflammatory effect, comparable to that of the reference drug - Kamistad. 
Table 4. The change of the concentration of leukocytes in the blood of rats after traumatic tooth injury.

\begin{tabular}{|c|c|c|c|c|c|}
\hline \multicolumn{6}{|c|}{ WBC, $10^{9}$ cells $/ 1$} \\
\hline Group & IA & NC & Kamistad & $\begin{array}{c}\text { Artemisia } \\
\text { scoparia }\end{array}$ & Gel base \\
\hline Day 3 & $3.80 \pm 0.143$ & $25.90 \pm 0.451 \#$ & $15.50 \pm 0.640^{*}$ & $16.50 \pm 0.384^{*}$ & $26.00 \pm 0.415$ \\
\hline Day 7 & $4.42 \pm 0.334$ & $30.68 \pm 0.604 \#$ & $13.15 \pm 0.767^{*}$ & $15.93 \pm 0.715^{*}$ & $33.88 \pm 1.295$ \\
\hline Day 10 & $3.40 \pm 0.200$ & $29.10 \pm 0.573 \#$ & $6.07 \pm 0.314^{*}$ & $4.68 \pm 0.158^{*}$ & $32.88 \pm 0.951$ \\
\hline Day 14 & $3.57 \pm 0.324$ & $30.20 \pm 1.472 \#$ & $\begin{array}{c}3.88 \pm 0.450^{*} \\
\text { Lymph, \% }\end{array}$ & $4.62 \pm 0.311^{*}$ & $30.17 \pm 0.883$ \\
\hline Group & IA & NC & Kamistad & $\begin{array}{l}\text { Artemisia } \\
\text { scoparia }\end{array}$ & Gel base \\
\hline Day 3 & $71.57 \pm 3.248$ & $72.60 \pm 1.242$ & $72.30 \pm 0.645$ & $65.52 \pm 1.660$ & $75.05 \pm 0,869$ \\
\hline Day 7 & $73.52 \pm 1.511$ & $55.37 \pm 0.457$ & $65.80 \pm 1.094$ & $64.48 \pm 0.772$ & $54.60 \pm 0,550$ \\
\hline Day 10 & $74.73 \pm 0.887$ & $54.38 \pm 1.623$ & $72.38 \pm 0.817$ & $74.33 \pm 0.784$ & $55.22 \pm 1.112$ \\
\hline Day 14 & $75.20 \pm 1.213$ & $55.30 \pm 1.192$ & $\begin{array}{l}74.60 \pm 0.857 \\
\text { Mon, } \% \\
\end{array}$ & $73.87 \pm 0.567$ & $56.50 \pm 1.207$ \\
\hline Group & IA & NC & Kamistad & $\begin{array}{c}\text { Artemisia } \\
\text { scoparia }\end{array}$ & Gel base \\
\hline Day 3 & $1,78 \pm 0,048$ & $2,82 \pm 0,07$ & $2,37 \pm 0,056$ & $2,28 \pm 0,079 *$ & $3,12 \pm 0,114$ \\
\hline Day 7 & $1,63 \pm 0,067$ & $3,38 \pm 0,065 \#$ & $2,53 \pm 0,071^{*}$ & $2,3 \pm 0,037^{*}$ & $3,58 \pm 0,079$ \\
\hline Day 10 & $1,7 \pm 0,058$ & $3,68 \pm 0,178 \#$ & $1,93 \pm 0,176^{*}$ & $1,9 \pm 0,159^{*}$ & $3,65 \pm 0,134$ \\
\hline Day 14 & $1,72 \pm 0,128$ & $3,65 \pm 0,099 \#$ & $\begin{array}{l}\text { 1,97 } \pm 0,186^{*} \\
\text { Gran, } \%\end{array}$ & $2,07 \pm 0,099^{*}$ & $3,72 \pm 0,166$ \\
\hline Group & IA & NC & Kamistad & $\begin{array}{c}\text { Artemisia } \\
\text { scoparia }\end{array}$ & Gel base \\
\hline Day 3 & $26.65 \pm 3.226$ & $24.58 \pm 1.259$ & $25.33 \pm 0.619$ & $22.20 \pm 1.697$ & $21.83 \pm 0.832$ \\
\hline Day 7 & $24.85 \pm 1.513$ & $41.25 \pm 0.431 \#$ & $31.67 \pm 1.078^{*}$ & $33.22 \pm 0.761^{*}$ & $41.82 \pm 0.514$ \\
\hline Day 10 & $23.57 \pm 0.873$ & 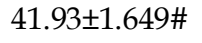 & $25.68 \pm 0.837^{*}$ & $23.77 \pm 0.875^{*}$ & $41.13 \pm 1.074$ \\
\hline Day 14 & $23.08 \pm 1.244$ & $41.05 \pm 1.124 \#$ & $23.43 \pm 0.882^{*}$ & $24.07 \pm 0.642^{*}$ & $39.78 \pm 1.219$ \\
\hline
\end{tabular}

Note: WBC - white blood cells; Lymph - lymphocytes; Mon - monocytes; Gran - granulocytes; \# - statistically significant relative to the group IA of rats (Newman-Keulse test, $\mathrm{p}<0.05)$; ${ }^{*}$ - statistically significant relative to the group $\mathrm{NC}$ of the rat group (Newman-Keulse test, $\mathrm{p}<0.05)$.

Table 5. Change of the C-reactive protein concentration in the blood of rats after traumatic tooth injury.

\begin{tabular}{cccccc}
\hline Group & IA & NC & Kamistad & Artemisia scoparia & Gel base \\
\hline Day 3 & $1.42 \pm 0.101$ & $9.52 \pm 0.305 \#$ & $6.45 \pm 0.272^{*}$ & $6.08 \pm 0.221^{*}$ & $9.97 \pm 0.337 \#$ \\
Day 7 & $1.45 \pm 0.076$ & $9.12 \pm 0.376 \#$ & $3.97 \pm 0.196^{*}$ & $4.60 \pm 0.169^{*}$ & $10.42 \pm 0.333 \#$ \\
Day 10 & $1.52 \pm 0.135$ & $8.70 \pm 0.41 \#$ & $2.82 \pm 0.263^{*}$ & $2.25 \pm 0.141^{*}$ & $8.92 \pm 0.275 \#$ \\
Day 14 & $1.60 \pm 0.089$ & $8.28 \pm 0.281 \#$ & $2.37 \pm 0.088^{*}$ & $2.07 \pm 0.156^{*}$ & $8.60 \pm 0.253 \#$ \\
\hline
\end{tabular}

Note: CRP - C-reactive protein; \# - statistically significant relative to the group IA of rats (Newman-Keulse test, $p<0.05$ );

* - statistically significant relative to the group NC of the rat group (Newman-Keulse test, $p<0.05$ ).

\section{MATERIALS AND METHODS}

The aerial part of Artemisia scoparia was collected during the budding phase in may in 2019 year - the beginning of flowering. The plants were dried in the shade at a temperature of $25-40^{\circ} \mathrm{C}$.

Specimens were collected in the Nikitsky Botanical Garden in 2019. Voucher specimens № 126-129 of Artemisia scoparia Waldst. et Kit. were deposited in the Herbarium Of The Pharmacognosy, Botany and Technology Phytopreperations Department, Pyatigorsk Medical and Pharmaceutical Institute, branch of the Volgograd State Medical University, Russia. The samples were identified by PhD Serebryana F.K samples.

Chlorogenic acid, umbelliferone, scopoletin, and scoparone (Sigma-Aldrich) were used as standard

For the analysis, the step gradient model was used (Table 1). As the mobile phase of the following composition: acetonitrile-formic acid aqueous solution of $0.1 \%$. The analysis was carried out at a wavelength of $280 \mathrm{~nm}$, using a column made of stainless steel Luna C18 (2) ("Phenomenex", USA) 250*4.6 mm. The flow rate is $0.7 \mathrm{ml} / \mathrm{min}$. The volume of the injected sample is $20 \mu \mathrm{l}$. The test-extract were injected once. The column temperature is $25^{\circ} \mathrm{C}$. 
Table 6. The step gradient model.

\begin{tabular}{ccc}
\hline Time, minutes & Amount of acetonitrile (\%) & Amount of formic acid (\%) \\
\hline $0-10$ & 15 & 85 \\
$10,0-10,1$ & 20 & 80 \\
$10,1-50$ & 20 & 80 \\
\hline
\end{tabular}

The extract was obtained by the bismaceration method (10 g of raw material and $100 \mathrm{ml}$ of solvent) using five and three times the amount of solvent. The resulting extract was concentrated and then dried in a vacuum oven to a dry extract (humidity $\pm 5 \%$ ). The gel was formed using the obtained dry extract. A copolymer of acrylic acid carbopol 940 was used as a gelling agent. The gel on this basis does not have a sensitizing and irritating effect on the skin, is well distributed over the mucous membranes and the skin surface.

The dry extract was added to the carbopol in parts until a gel of $1 \%$ concentration was obtained. The gel was actively mixed until the distribution of the dry extract was completely uniform. This gel was used for pharmacological tests.

The study was performed on 36 Wistar male rats weighing 220-240 grams. The animals were kept under controlled vivarium conditions at an ambient temperature of $22 \pm 2{ }^{\circ} \mathrm{C}$, relative humidity $55 \pm 5^{\circ} \mathrm{C}$ and a natural change in the daily cycle. Before use in experimental studies, animals were quarantined for 14 days. The contents and all the manipulations carried out with rats were in accordance with the norms of the "European Convention for the Protection of Vertebrate Animals used for Experimental and Other Scientific Purposes" (Strasbourg, 1986) and GOST 33044-2014 "Principles of Good Laboratory Practice" [12, 13]. The study was approved by the local ethics committee (Protocol No. 12 of 01.04.2017).

\subsection{The traumatic model of tooth injury}

Tooth damage was modeled by inserting a thin-walled needle G 21 into the interdental space to a depth of $1 \mathrm{~mm}$ (Figure 8) [14].

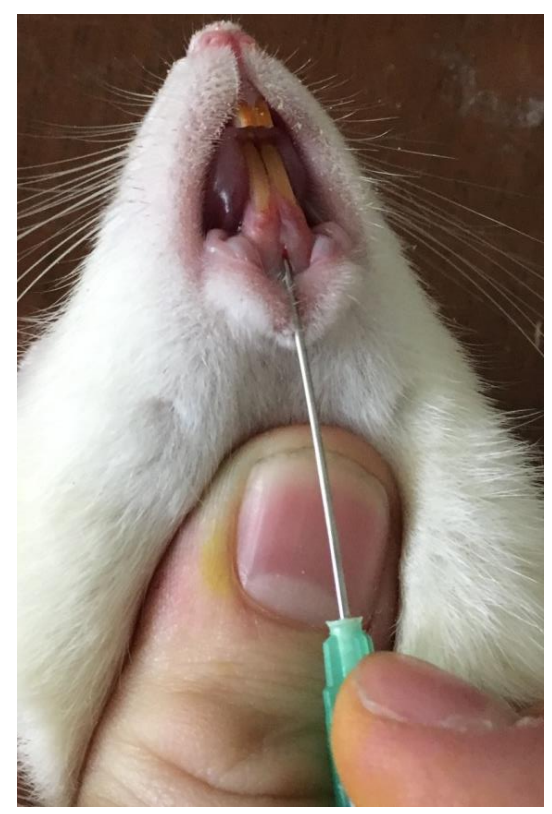

Figure 8. The experimental model of traumatic tooth damage.

\subsection{The study design}

The duration of the experiment was 14 days. The test-objects were a wormwood-based gel $(n=6)$ and a comparison gel - Kamistad (Stada Arzneimittel AG, Germany) $(n=6)$, as well as a gel base ( $n=6)$, which was applied daily after modeling an injury to the surface of a wound defect for 14 days. An intact group of rats $(\mathrm{IA}, \mathrm{n}=6)$ and a group of animals of a negative control $(\mathrm{NC}, \mathrm{n}=6)$, lacking pharmacological support, were formed. On the 3rd; 7th; 10th and 14th day blood was taken from the animals. In blood samples determined of the total concentration of leukocytes and leukoformula, the content of C-reactive protein (CRP).Also made a macroscopic assessment of changes in the state of the dental space. 


\subsection{Determination of the concentration of white blood cells in the blood}

The blood leukocyte content and leukoformula (the percentage ratio of lymphocytes, monocytes and granulocytes) were determined using a BC-2400 vet veterinary automatic hematology analyzer system (Minray, China) in rat citrate blood, which was taken from the hyoid vein.

\subsection{Determination of the concentration of $\mathrm{C}$ - reactive protein}

The content of $\mathrm{C}$ - reactive protein (CRP) was determined by the semiquantitative method using a standard reagents kit manufactured by Arbis + (St. Petersburg, Russia). The principle of the method is based on the reaction of the interaction between CRP and antibodies fixed on the surface of latex-particles specific to CRP with the formation of agglutinates. The sample processing and analysis progress corresponded to the instructions attached to the reagent kit.

\subsection{Methods of statistical processing of research results}

The experimental results were processed by the method of variation statistics using the STATISTICA 6.0 application package (StatSoft, Inc., USA for the Windows operating system) and Microsoft Excel version 10. The mean and standard error of the mean were calculated. Data were expressed as M \pm SEM. Comparison of groups of mean values was performed by the method of one-way ANOVA test with the Newman-Keulse post-test at $\mathrm{p}<0.05$.

Author contributions: Concept - DK; Design - DK, DP, EA; Supervision - DK; Resources - DK, DP, EA; Materials DK, EA; Data Collection and/or Processing - DK, DP, EA; Analysis and/or Interpretation - DK, DP; Literature Search- EA; Writing - DK, DP, EA; Critical Reviews - DK, DP, EA.

Conflict of interest statement: The authors declare that they have no competing interests.

Ethics committee approval: The study was approved by the local ethics committee (Protocol No. 12 of 01.04.2017).

\section{REFERENCES}

[1] Habib M, Waheed I. Evaluation of anti-nociceptive, anti-inflammatory and antipyretic activities of Artemisia scoparia hydromethanolic extract. J Ethnopharmacol. 2003; 145(1): 18-24. [CrossRef]

[2] Konovalov DA, Konovalova OA, Chelombitko VA. Chemical composition of the essential oil of Artemisia scoparia. Chem Nat Compd. 1992; 28(1): 121-122. [CrossRef]

[3] Konovalov DA. Natural polyacetylene compounds. Pharm Pharmacol. 2014; 4(5): 23-48. [CrossRef]

[4] Singh D, Rawat M, Garg G, Saraf S, Saraf S. Artemisia scoparia: a review. Pharm Mag. 2006; 2(5): 27-30.

[5] Boudreau A, Richard AJ, Burrell JA, King WT, Dunn R, Schwarz JM, Ribnicky DM, Rood J, Salbaum JM, Stephens JM. An ethanolic extract of Artemisia scoparia inhibits lipolysis in vivo and has antilipolytic effects on murine adipocytes in vitro. Am J Physiol-Endocrinol Metab. 2018; 315(5): 1053-1061. [CrossRef]

[6] Boudreau A, Poulev A, Ribnicky DM, Raskin I, Rathinasabapathy T, Richard AJ, Stephens JM. Distinct fractions of an Artemisia scoparia extract contain compounds with novel adipogenic bioactivity. Front Nutr. 2019; 6: 18. [CrossRef]

[7] Nam SY, Han NR, Rah SY, Seo Y, Kim HM, Jeong HJ. Anti-inflammatory effects of Artemisia scoparia and its active constituent, 3,5-dicaffeoyl-epi-quinic acid against activated mast cells. J Immunopharmacol Immunotoxicol. 2018; 40: 52-58. [CrossRef]

[8] Naveed M, Hejazi V, Abbas M, Kamboh AA, Khan GJ, Shumzaid M, WenHua L. Chlorogenic acid (CGA): A pharmacological review and call for further research. Biomed Pharmacother. 2018; 97: 67-74. [CrossRef]

[9] Ahmadi N, Mohamed S, Sulaiman Rahman H, Rosli R. Epicatechin and scopoletin-rich Morinda citrifolia leaf ameliorated leukemia via anti-inflammatory, anti-angiogenesis, and apoptosis pathways in vitro and in vivo. J Food Biochem. 2019; 43(7): e12868. [CrossRef]

[10] Yin J, Wang H, Lu G. Umbelliferone alleviates hepatic injury in diabetic $\mathrm{db} / \mathrm{db}$ mice via inhibiting inflammatory response and activating Nrf2-mediated antioxidant. Biosci Rep. 2018; 38(4): BSR20180444. [CrossRef]

[11] Lu C, Li Y, Hu S, Cai Y, Yang Z, Peng K. Scoparone prevents IL-1 $\beta$-induced inflammatory response in human osteoarthritis chondrocytes through the PI3K/Akt/NF-kB pathway. Biomed Pharmacother. 2018; 106: 1169-1174. [CrossRef] 
[12] Council of Europe. European convention for the protection of vertebrate animals used for experimental and other scientific purposes. Council Eur. 1986; 18. III.

[13] GOST R. 33044-2014. Printsipy nadlezhashchey laboratornoy praktiki [Principles of Good Laboratory Practice].

[14] Kantarci A, Hasturk H, Van Dyke TE. Animal models for periodontal regeneration and peri-implant responses. Periodontol. 2000. 2015; 68(1): 66-82. [CrossRef]

[15] Petrič AD, Lukman T, Verk B, Svete A N. Systemic inflammation in dogs with advanced-stage heart failure. Acta Vet Scand. 2018; 60(1): 20. [CrossRef]

This is an open access article which is publicly available on our journal's website under Institutional Repository at http://dspace.marmara.edu.tr. 